\title{
TRANSLOCATION HETEROZYGOSITY AND THE ORIGIN OF DIOECY IN VISCUM
}

\author{
D. WIENS* and B. A. BARLOW† \\ * Department of Biology, University of Utah, Salt Lake City, \\ Utah 84112; $†$ School of Biological Sciences, Flinders University, \\ Bedford Park, South Australia 5042
}

Received 21.x.78

\begin{abstract}
SUMMARY
Sex-associated and floating translocation complexes are characteristic of dioecious species of Viscum, but are virtually absent in monoecious species. In most of the dioecious species, fixed sex-associated translocation complexes are present, with the male being the heterozygous sex. The sex-associated multivalent is usually $\odot 4$ (ring-of-four) or $\odot 6$, rarely $\odot 8$. In only a few of the dioecious species are sex-associated translocations not apparent. Most of the dioecious species are also polymorphic for floating translocations, producing one or more additional multivalents ranging from $\odot 4$ to $\odot 12$. Floa ing translocations may be more frequent in species which do not have sex-associated translocations. Supernumerary chromosomes are also present in several species. Sex ratios are at unity in most dioecious species, but female-biased ratios as low as 0.52 and male-biased ratios as high as 1.40 may occur in some species. The high correlation between dioecy and translocation heterozygosity suggests that translocations are primarily associated with the origin and establishment of dioecy, and any role they play in the maintenance of biased sex ratios through meiotic drive is probably secondary. A model is presented in which male- and female-determining factors are non-allelic, and sex-associated translocations serve to stabilise dioecy by bringing the sex factors into linkage. Subsequent structural rearrangements within a sex-associated translocation complex may bring the sex factors together in one chromosome pair, releasing floating translocations. The high frequencies of floating translocation heterozygosity in some species indicate that such heterozygosity has adaptive value.
\end{abstract}

\section{InTRODUGTion}

Viscum is a genus of mistletoes comprising about 100 species, and has an extensive range in the Old World. Its species parasitise a wide range of dicotyledonous trees and shrubs in a variety of forest and woodland habitats. Major centres of species diversity are Africa and Madagascar, but there is also a significant development of the genus in tropical and subtropical Asia. The extremes of the range of the genus are reached by a few species in Europe and temperate Asia, and by a few others in Indomalaya and Australia.

The flowers in Viscum are small and consistently unisexual. The basic inflorescence unit is a small cymule, usually consisting of three flowers, but in some species the flowers are solitary or in larger clusters. The majority of species are monoecious, typically having the central flower of the cymule of one sex and the two lateral flowers of the other. Monoecious species occur throughout the range of the genus except for Europe and temperate Asia.

Dioecious species are common in Africa and Madagascar, and a few others are widely distributed in Europe and temperate Asia. In the dioecious species the cymules are still typically three-flowered, so that 
dioecy presumably involves a possibly simple conversion of all Howers to the same sex for all cymules of a plant. Dioecy appears to be highly stable in its expression in Viscum, and mixed cymules are unknown in any of the dioecious entities we have studied.

The most common chromosome number among the African species is $x=14$, and this appears to be the basic number for the genus (Wiens, 1975). The Madagascan species so far examined mostly have $x=13$, but more extensive data are needed. Some of the Madagascan species are more closely related to the Visca of the Asian region than to those of Africa. Lower basic numbers of aneuploid derivation are general in the northern, southern, and eastern extremities of the range of the genus, and Wiens (1975) has indicated that tropical Africa is its probable centre of distribution.

Translocation heterozygosity was first reported for Viscum in the dioecious species, $V$. fischeri Engl. from Kenya (Wiens and Barlow, 1973, 1975). Male plants of this species have a chromosome number of $2 n=23$, and consistently produce seven bivalents and an open multivalent chain of nine chromosomes at meiosis. Regular alternate orientation and disjunction in the chain results in $4 / 5$ segregation, so that 11 - and 12-chromosome genomes are transmitted via the pollen. Female plants consistently have $2 n=22$, and produce 11 bivalents at meiosis, apparently being homozygous for the 11-chromosome genome. Translocation heterozygosity is therefore presumed to be sex-associated, with the male being the heterozygous sex and the 11- and 12-chromosome genomes being female-determining and maledetermining, respectively. More detailed studies of $V$. fischeri revealed a strongly female-biased sex ratio of approximately $1: 2$, which we suggested was associated with a meiotic drive mechanism in response to selection for a biased sex ratio (Barlow and Wiens, 1976).

Further studies have indicated that sex-associated translocations are widespread in dioecious species of Viscum. In V. hildebrandtii Engl. and $V$. engleri Tiegh. from East Africa, male plants are always heterozygous for translocations producing a ring multivalent, usually $\odot 4$ (ring-of-four) or $\odot 6$ (Barlow and Wiens, 1975). In $V$. album L. and $V$. cruciatum Boiss. from Europe and Asia, male plants always have $\odot 8$ or $\odot 10$, while females are in some cases homozygous and in other cases heterozygous for different translocation complexes (Barlow et al., 1978). No consistent pattern of sex ratios occurred in these species, with $V$. engleri and $V$. hildebrandtii showing a slight excess of male plants while $V$. album and $V$. cruciatum exhibited a large excess of female plants.

A more extensive cytogenetic survey of the African species of Viscum is presented in this paper. Field work has extended over much of eastern and southern Africa, from Ethiopia to the Cape, and the survey has included both monoecious and dioecious species. The occurrence and distribution of translocation heterozygosity and also of supernumerary chromosomes are described and considered in relation to the origin and establishment of dioecy and to variations in the sex ratio. For completeness of this account, previously published data for the African species are included in the Appendix.

\section{Methods}

Flower buds were fixed in ethyl alcohol/acetic acid $(3: 1)$ and stored in absolute alcohol at $-15^{\circ} \mathrm{C}$ whenever possible. Chromosomal con- 
stitution was determined from aceto carmine squash preparations of pollen mother cell, or embryo sac mother cell meiosis in some female plants. The latter involved dissection of a block of tissue containing the sporogenous cells from the base of the flower bud (there are no discrete ovules in Viscum), maceration in a solution of 1 per cent $\mathrm{HCl}$ in 45 per cent acetic acid on a slide for $2 \mathrm{~min}$ at $60^{\circ} \mathrm{C}$, and light squashing.

The sex ratio for most species was determined directly from established populations in the field. Plants were mostly removed from the host for counting, so that difficulties caused by clumped distributions and autoparasitism could be minimised.

Voucher specimens for each sample are deposited at one or more of the following herbaria: State Herbarium of South Australia (AD), East African Herbarium (EA), University of Nairobi (NAI), Botanical Research Institute, Pretoria (PRE), Garrett Herbarium, University of Utah (UT).

\section{RESUlTS AND DISGUSSION}

Over 550 determinations of chromosomal constitution were made from an estimated 32 species and one subspecies, of which 12 entities are monoecious and 21 are dioecious. Details of these determinations are given in the Appendix. Selected characteristic configurations are illustrated in fig. 1 .

\section{(i) Monoecious species}

In 11 of the 13 monoecious entities examined the floral distribution was constant and typical of monoecious species, with each inflorescence cymule bearing both male and female flowers, with a central flower of one sex and lateral flowers of the other. In $V$. capense subsp. hoole $i$ Wiens the expression of monoecy was altered. Some plants produced mostly female flowers which had basically female morphology, while other plants produced mostly flowers of typical male morphology and matured few fruits. The vegetative characters of $V$. capense subsp. hoolei agree generally with the dioecious $V$. capense subsp. capense, thus in subsp. hoolei monoecy probably represents a derived state resulting from modification of sex determination in a dioecious species. In $V$. sp. C. aff. hildebrandtii a similar condition occurs in which the plants are primarily female with only the occasional occurrence of a male flower. Furthermore, in this species male flowers develop primarily as a result of converting stigmatic tissue to anther production. In $V$. sp. F. aff. shirense male and female flowers were produced together only at certain times, while at other times only female flowers were produced, a relatively common occurrence in monoecious species (Danser, 1941).

The chromosomal data for the monoecious entities are summarised in table 1. There is a general absence of translocation heterozygosity in these species, its only occurrence being recorded in a single individual of $V$. capense subsp. hoolei which had $8 \mathrm{II}+\odot 4$. This is in striking contrast to the situation in the dioecious species, where translocation heterozygosity is probably universal, at least in male plants (see below). As previously mentioned, in $V$. capense subsp. hoolei monoecy may be derived from dioecy, so that the translocation heterozygosity present may be the same as that found in the dioecious subspecies.

The variation in chromosome number among the monoecious species is 
from $n=10$ to $n=28$. Three of the 13 entities examined were consistently polyploid, but one tetraploid individual was discovered in $V$. capense subsp. hoolei, which is otherwise diploid. This situation contrasts sharply with that in the dioecious species, where triploidy and tetraploidy occurred, respectively, in one individual of $V$. verrucosum, and in $V$. multiflorum from Madagascar (Wiens, 1975). Although alternative explanations are possible the rarity of polyploidy in the dioecious species could be related to a mechanism where sex is determined by a balance between strongly femaleand male-determining $\mathrm{X}$ and $\mathrm{Y}$ factors, as originally proposed by Muller (1925).

\section{TABLE I}

Summary of chromosome constitutions in monoecious species of $\mathrm{Viscum}$ in Africa

\begin{tabular}{|c|c|c|c|}
\hline & \multirow{2}{*}{$\begin{array}{c}\text { Chromosome No. } \\
(n)\end{array}$} & \multicolumn{2}{|c|}{ No. of plants } \\
\hline & & Bivalents only & $\odot 4$ \\
\hline$V$. capense subsp. hoole ${ }^{*}$ & 10 & 10 & 1 \\
\hline V. minimum & 14 & 1 & - \\
\hline V. nervosum & 14 & 6 & - \\
\hline V. obovatum & 12 & 5 & - \\
\hline V. rotundifolium & 14 & 20 & - \\
\hline V. schimperi & 28 & 4 & - \\
\hline V. sp. E. aff. shirense* & 14 & 1 & - \\
\hline V. spragueanum & 23 & 1 & - \\
\hline V. tuberculatum & 23 & 8 & - \\
\hline V. sp. C. aff. hildebrandtii* & 28 & 1 & - \\
\hline V.sp. J. & 14 & 2 & - \\
\hline V. sp. K. & 14 & 1 & - \\
\hline
\end{tabular}

(ii) Example of a dioecious species--Viscum hildebrandtii

The data for $V$. hildebrandtii are summarised in table 2 as an example of the chromosomal diversity found in many of the dioecious species. All male plants are heterozygous for at least one translocation complex. However, most of the female plants are homozygous, producing only bivalents. Comparison of the data for male and female plants in each population shows that where male plants occur with more than one translocation ring, the additional rings also occur in female plants with comparable frequencies. For example, in the Riandu population all male plants have $\odot 6$, and some male plants have an additional $\odot 4$ and/or $\odot 6$. In the female plants $\odot 4$ and $\odot 6$ were recorded as well as a homozygote with 14II. This strongly supports our earlier suggestion (Barlow and Wiens, 1975) that there is one translocation ring which is sex-associated, and fixed in males as the heterozygous sex, while the other rings are floating and not sex-associated. Thus heterozygous and homozygous translocation complexes can occur in either sex.

Comparison of the different population samples in $V$. hildebrandtii indicates that at least two different sex-associated complexes are present in the species. In the Riandu and Thika populations only a sex-associated $\odot 6$ appears to be present, while in the Voi population only a sex-associated $\bigcirc 4$ is present. The Kajiado and Namanga populations are more complex, and male plants have either a sex-associated $\odot 6$ or $\bigcirc 4$. The single record of 
Frg. 1.-Meiotic configurations in dioecious African species of Viscum. Multivalents are indicated by arrows. Bars represent $25 \mu \mathrm{m}$; all configurations illustrated (except $\mathrm{b}$ and e) are at the same magnification as a. a, male $V$. oreophilum, W5311, 14II; b, female $V$. hildebrandtii, B2205, $14 \mathrm{II}$; c, male $V$. anceps, W5366b, $12 \mathrm{II}+\bigcirc 4$; demale V. hildebrandtii, $\mathrm{B} 2133,12 \mathrm{II}+\odot 4$; e, male $V$. combreticola, W5316c, $11 \mathrm{II}+\odot 6 ; \mathrm{f}$, male $V$. subserratum, W5305f, 8II + $\odot 6$; g, male $V$. subserratum, W5305b, 7II $+2 \bigcirc 4 ; \mathrm{h}$, male V. verrucosum, W5304a, $9 \mathrm{II}+\bigcirc 4+\bigcirc 6 ; \mathrm{j}$, male $V$. obscurum, W5356, $10 \mathrm{II}+\bigcirc 10$, showing multivalent disjoining precociously. 


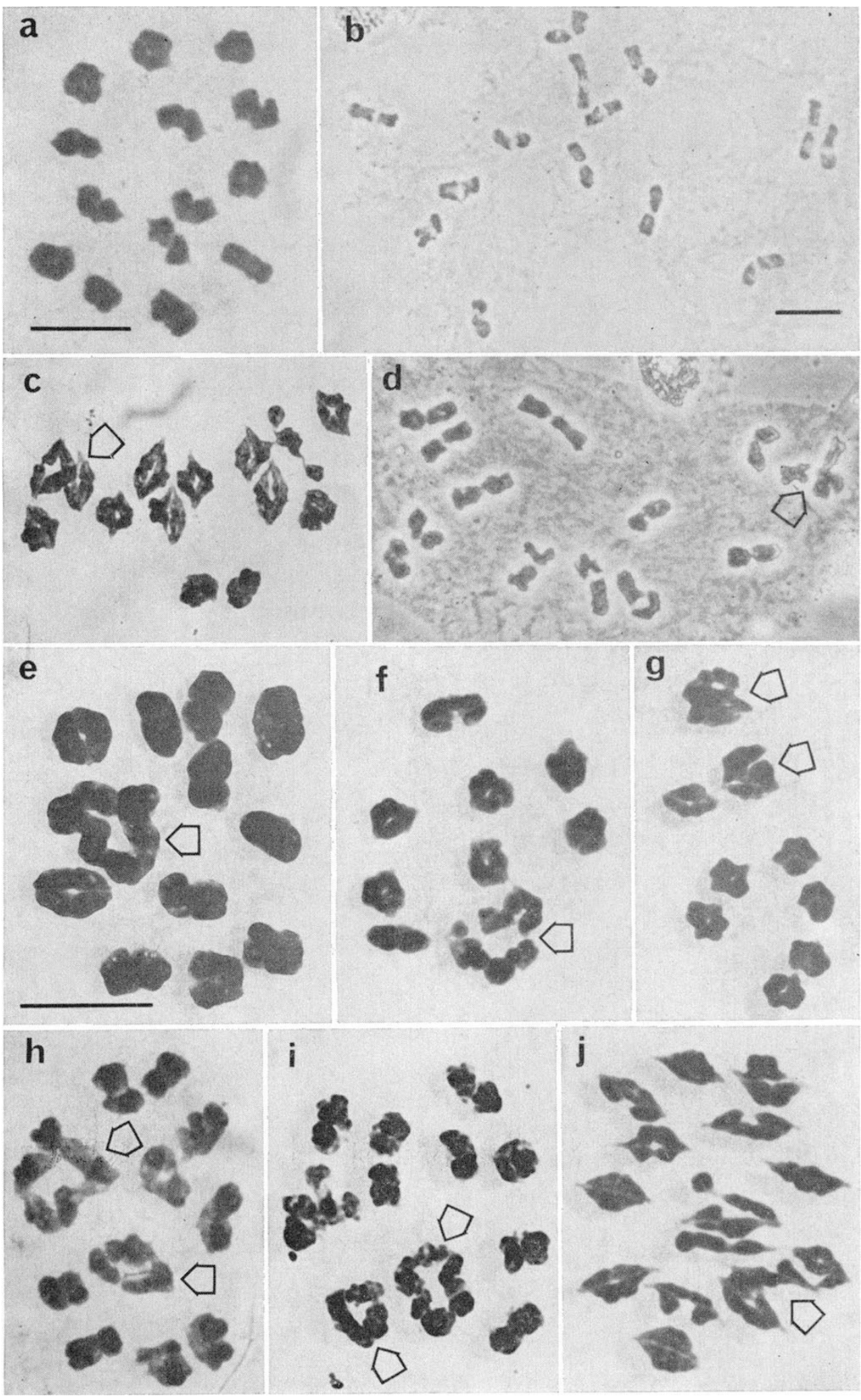




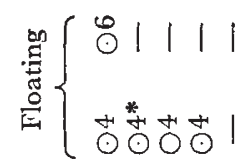

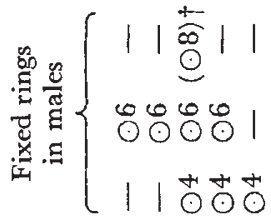
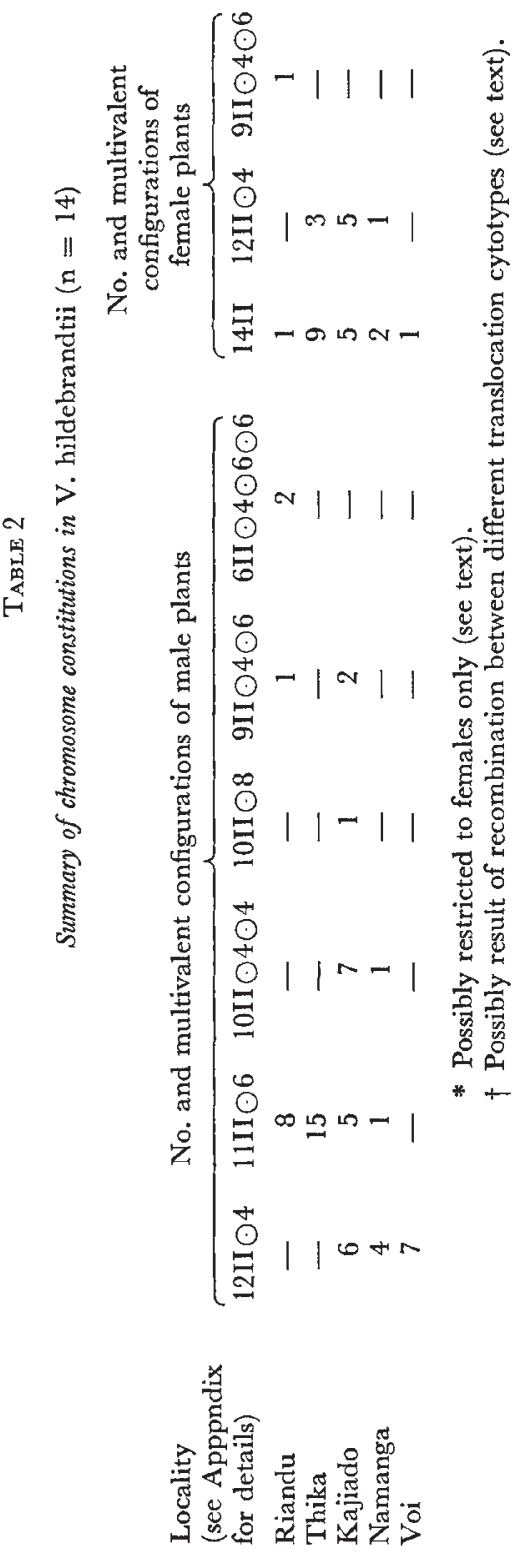
$10 \mathrm{II}+\odot 8$ from Kajiado indicates the presence of an additional larger sexassociated complex, but it may be explained in terms of recombination between other cytotypes in the population (Barlow and Wiens, 1975).

In the Thika population $\odot 4$ was observed in 3 out of 12 female plants examined, but was not seen in any of the 15 male plants examined. If this translocation is a simple floating one, it should be found in both sexes. While scores for male and female plants are not significantly different because of the small samples $\left(\chi^{2}=2 \cdot 1 ; 0.25>\mathrm{p}>0.10\right)$, the absence of

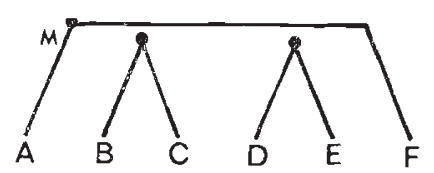

male-defermining complex
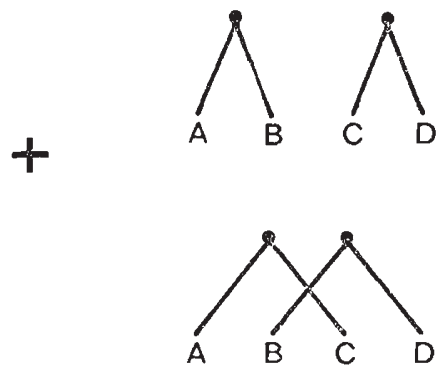

female-determining

complexes

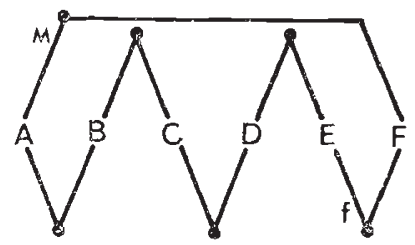

$\downarrow$
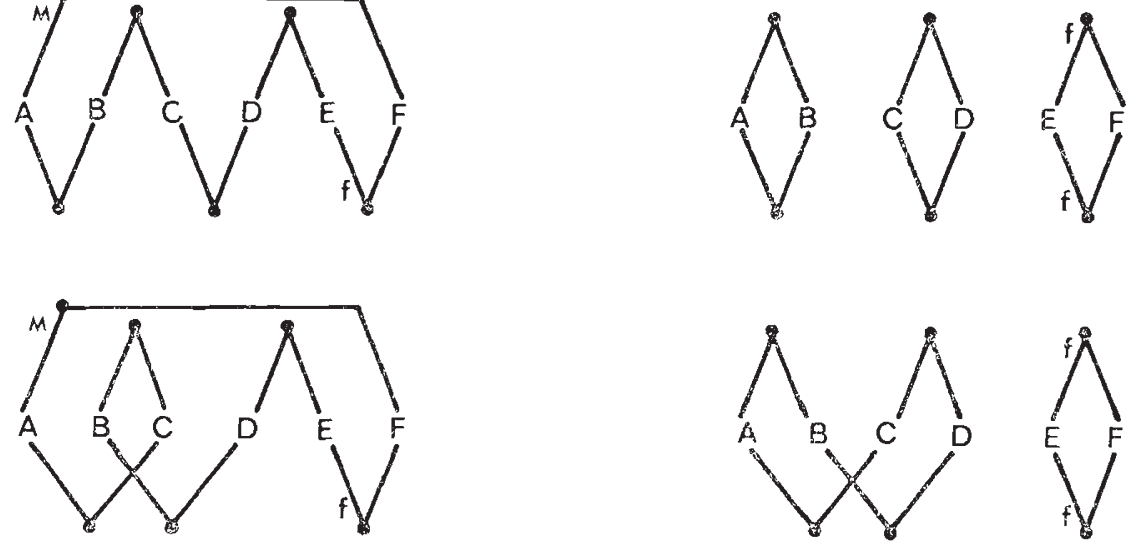

males with sex-associated 06

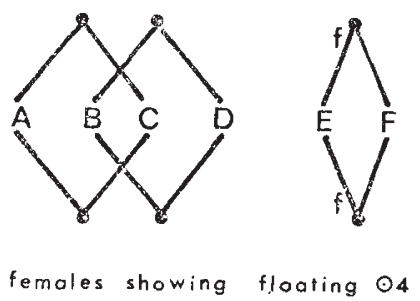

FIG. 2.- Model for the occurrence of a floating $\odot 4$ restricted to female plants. 
$\odot 4$ in the male plants examined indicates that the translocation might be sex-associated in the sense that it only occurs in the heterozygous state in female plants, even though it is floating in the sense that individual female plants can either be heterozygous or homozygous. A possible model is shown in fig. 2.

Differences between most local populations of $V$. hildebrandtii occur with respect to $(a)$ which sex-associated translocation complex is present, $(b)$ which floating translocation complexes are present, and $(c)$ the frequencies of the floating translocation complexes present. As suggested previously (Barlow and Wiens, 1975), these structural rearrangements may be associated with biotype differentiation in the species.

\section{(iii) Dioecious species}

The chromosome constitutions of all of the dioecious African species examined are summarised in table 3 , and representative configurations are illustrated in fig. I. Translocation heterozygosity obviously has a high frequency, and occurs in almost all dioecious species. The 20 species are grouped according to the patterns of translocation heterozygosity they exhibit.

The largest group of 13 species exhibit patterns consistent with that described for $V$. hildebrandtii. In these species male plants always had at least one ring. Female plants, where examined, were consistent with the assumption that some rings occur in male plants only.

In some respects the species in this group are chromosomally relatively uniform. With the exception of $V$. subserratum $(n=11)$, all species in the group have $n=14$ and a generally symmetrical karyotype. The most common sex-associated rings are $\odot 4$ and $\odot 6$, and in at least 8 of the 13 species both rings are present. A floating $\odot 4$ is present in at least 10 of the 13 species.

A few differences are superimposed on this common pattern. A sexassociated $\odot 8$ occurs in $V$. combreticola and $V$. sp. E. as well as in $V$. hildebrandtii (see above). Its occurrence may be linked with the presence of a sex-associated $\odot 6$, which appears to be common in these three species. In one species ( $V$. combreticola) there is evidence for two independent floating $\odot 4$ s. A floating $\odot 6$ occurs in only three species and in one of these $(V$. sp. H.) the few determinations may also be interpreted as indicating sexassociated $\odot 4$ and $\odot 6$ and floating $\odot 4$. The latter interpretation is more consistent with the pattern found in other species.

In the species of this group, then, the sex-associated complex consistently appears in males as $\odot 4$ or $\odot 6$, and in addition, most species have a floating $\odot 4$. This regular pattern suggests that the sex-associated translocations (and possibly also the floating ones) may be the same in most or all of the species in the group. If so, the translocation system may be relatively old, established prior to the differentiation of the extant species. The accumulation of linked complexes through the translocations may have promoted rapid differentiation of biotypes, and the uniformity of chromosome number among these species is consistent with this possibility.

Viscum fischeri remains singular as the second group, in having a single open sex-associated multivalent of nine chromosomes (Wiens and Barlow, 1973, 1975). This is presumably a consequence of the asymmetry of the 


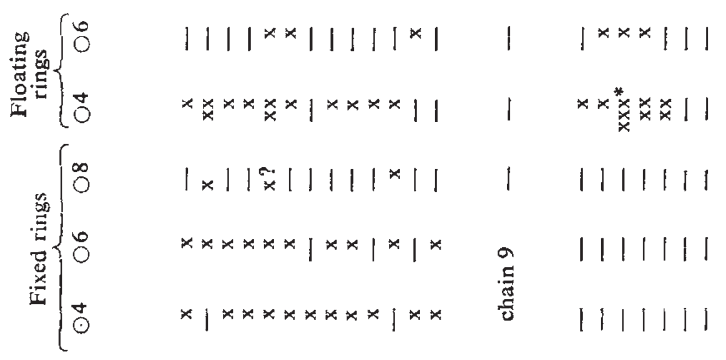

(

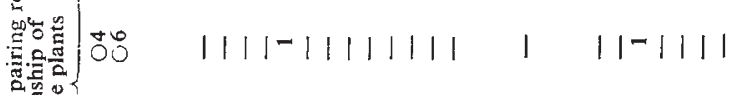

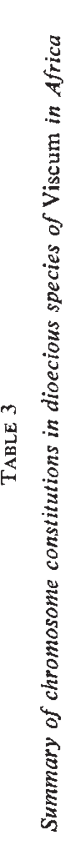

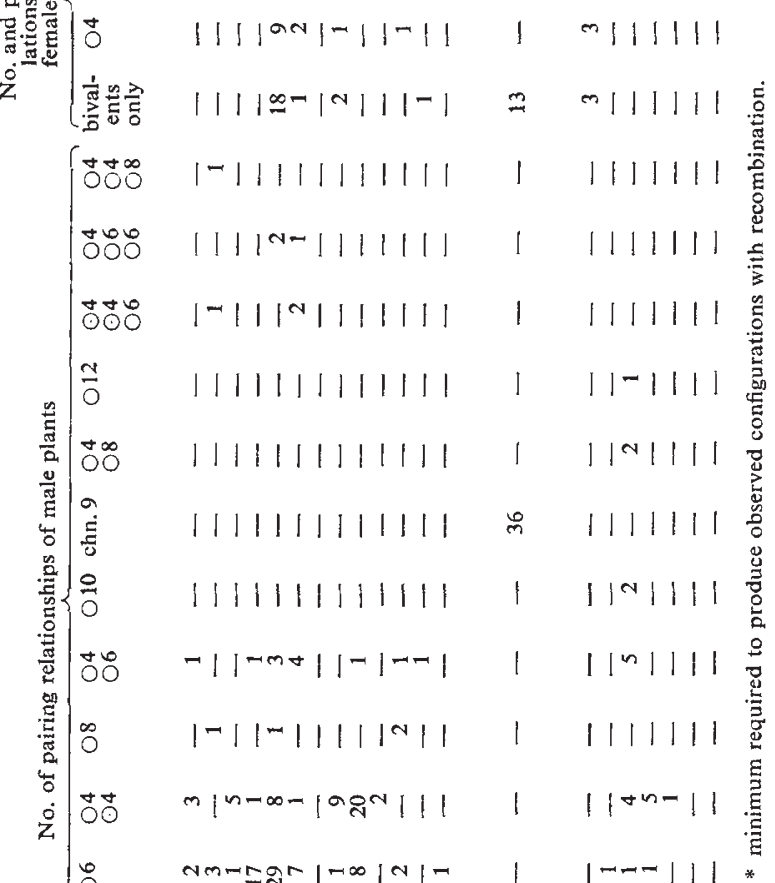

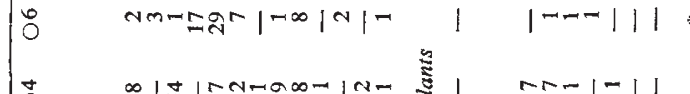

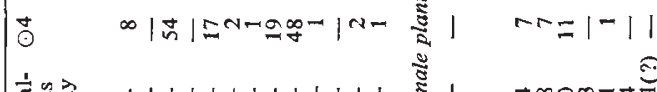

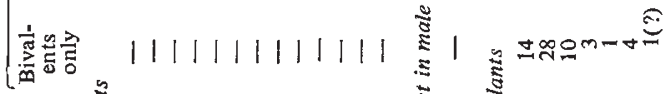

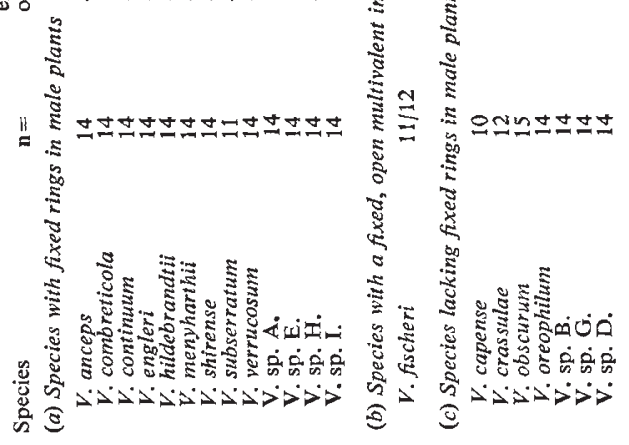


genome of the species, which has resulted in a Robertsonian translocation being included in the sequence (Barlow and Wiens, 1976). This species is also unusual in its uniformity, having the same sex-associated multivalent in all male plants examined and no floating multivalents.

The third group includes the remaining six species, of which four have different chromosome numbers $(n=10,12,14,15)$. In these species some of the male plants had 14II, indicating that fixed sex-associated complexes are not present. With the exception of $V$. sp. G. aff. verrucosum (from which few determinations of chromosome configurations are available), there is evidence of extensive floating translocation heterozygosity, presumably in female plants as well as males. In fact, floating translocations are apparently more frequent in these species than in those of the first group. In $V$. oreophilum and $V$. sp. B. aff. goetzii two floating $\odot 4$ s occur. Viscum obscurum contains the most extreme complexity, where associations up to $\odot 12$ were found, and individuals with two rings were relatively common. The minimum number of floating translocations needed to produce these associations in $V$. obscurum is five, assuming that all configurations observed represent recombinations of the same translocations.

Perhaps the species in this group represent a transitional stage in the evolution of the sex-associated translocation system, with the floating translocations acquired first and later linked with the sex-determining chromosomes by subsequent translocations. However, this group contains both highly specialised and diverse species, as indicated by their morphology and range of chromosome numbers. They may, therefore, represent a derived state, in which sex-associated multivalents have been released from linkage with the sex-determining chromosomes by subsequent translocations. These would then become floating multivalents. This hypothesis is consistent with the observation that the species in this group have a greater diversity of floating multivalents than the species in the preceding group. In other words, sex-associated multivalents were possibly acquired early in the evolution of the genetic system, and later converted to floating associations by subsequent exchanges. This appears to us as the best explanation and is discussed further.

\section{(iv) Frequencies of floating translocations}

The data indicate that the frequencies of floating translocations vary between populations in some species. Estimates of the frequencies of floating $\odot 4$ for a few species in which some analysis is possible are given in table 4 .

In $V$. verrucosum the frequency of the heterozygote with the floating $\odot 4$ may vary significantly between populations, from zero to the theoretical maximum of 0.5 , with corresponding variations in gametic frequencies of the translocation complexes. Similar variations appear to occur in some of the other species listed. However, because of the small sample sizes it is not possible to determine the frequencies with high levels of confidence, and the calculated frequencies in table 4 can only be regarded as a general indication of the scale of variation.

If the high frequencies of heterozygosity recorded for some populations are real, then positive selection favouring the heterozygotes is indicated. If the translocation complexes maintain adaptive gene combinations, there must be interaction between suites of genes in the complementary chromosome complexes, thus generating heterozygote advantage. Bloom (1977) 


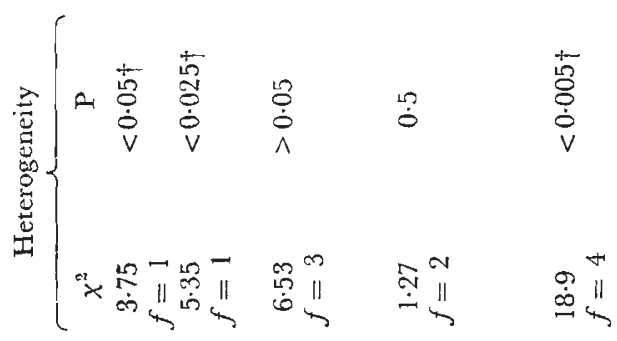
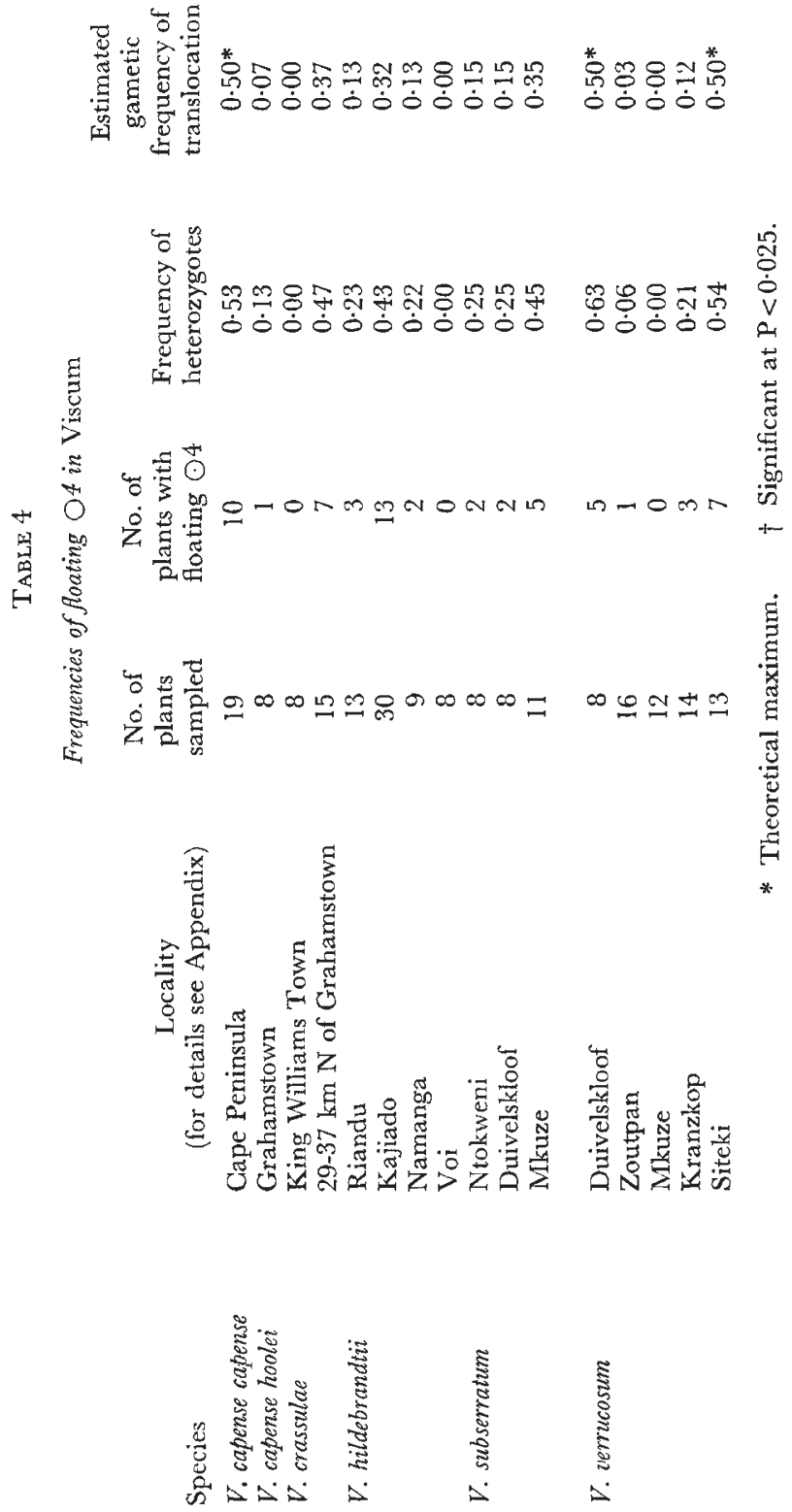
has shown in Clarkia that translocation heterozygosity is maintained because of the levels of inbreeding which might be imposed on natural populations. This argument could apply to Viscum, which as a generally highly hostspecific parasite often occurs in small, relatively isolated local populations, probably derived from a few founder individuals.

\section{(v) Supernumerary chromosomes}

A single supernumerary (B-) chromosome was observed in some individuals of a few dioecious species ( $V$. capense, $V$. obscurum, $V$. shirense, $V$. verrucosum, and $V$. sp. G. aff. verrucosum). In addition at least three different B-chromosomes are widespread over the range of $V$. album in Europe and Asia (Mechelke, 1976; Barlow et al., 1978; Barlow and Wiens, unpublished data). Although B-chromosomes are presently known only in dioecious species, they appear not to be necessarily associated with the dioecious state. The B-chromosomes in Viscum have probably originated as centric fragments resulting from chromosome breakage, reunion, and segregation, a mode of origin proposed for a number of plant groups (John, 1976).

TABLE 5. Sex ratios in some dioecious African species of Viscum

\begin{tabular}{|c|c|c|c|c|c|c|}
\hline & & No. of & plants & & & \\
\hline Species & $\begin{array}{c}\text { Locality } \\
\text { (for details see appendix) }\end{array}$ & Male & Female & Sex ratio & $\chi^{2} \exp .1 \cdot 00$ & $\chi^{2}$ exp. 0.75 \\
\hline$V$. anceps & $12 \mathrm{~km} \mathrm{~W}$ of Port St. John & 12 & 11 & $1 \cdot 09$ & 0.04 & - \\
\hline$V$. capense & Cape Peninsula & 133 & 110 & $1 \cdot 21$ & $2 \cdot 18$ & 一 \\
\hline$V$. continuum & Calitzdorp & 9 & 11 & $0 \cdot 82$ & $0 \cdot 20$ & - \\
\hline & De Rust & 28 & 33 & 0.85 & 0.41 & - \\
\hline & Oudtshoorn & 59 & 60 & 0.98 & 0.00 & - \\
\hline & Laingsburg & 54 & 47 & $1 \cdot 15$ & 0.49 & 一 \\
\hline & Worcester & 16 & 19 & 0.84 & 0.26 & - \\
\hline & Bonnievale & 29 & 48 & 0.60 & $4 \cdot 69 *$ & - \\
\hline & Stormsvlei & 13 & 14 & 0.93 & $0 \cdot 02$ & - \\
\hline & & $\overline{208}$ & $\overline{232}$ & $\overline{0.90}$ & $\overline{1 \cdot 30}$ & 一 \\
\hline$V$. crassulae & King Williams Town & 10 & 6 & $1 \cdot 67$ & $0 \cdot 50$ & - \\
\hline$V$. engleri & Lushoto (Barlow and Wiens, 1975) & 29 & 25 & $1 \cdot 16$ & $0 \cdot 30$ & - \\
\hline$V$. fischeri & Kenya (Barlow and Wiens, 1976) & 64 & 124 & 0.52 & $19 \cdot 2 * *$ & - \\
\hline V. hildebrandtii & Kenya (Barlow and Wiens, 1975) & 87 & 58 & $1 \cdot 40$ & $3 \cdot 81$ & - \\
\hline V. menyharthii & Wyliespoort & 22 & 19 & $1 \cdot 16$ & 0.22 & - \\
\hline V. obscurum & Pretoriuskop & 5 & 6 & $0 \cdot 83$ & 0.09 & 0.03 \\
\hline & King Williams Town & 29 & 28 & $1 \cdot 04$ & 0.02 & $1 \cdot 52$ \\
\hline & Grahamstown & 44 & 70 & 0.63 & $5.93 *$ & 0.86 \\
\hline & Avontuur & 39 & 48 & $0 \cdot 81$ & 0.93 & $0 \cdot 16$ \\
\hline & & 117 & 152 & 0.77 & $4.55 *$ & 0.05 \\
\hline$V$. subserratum & Ntokweni & 36 & 49 & $0 \cdot 73$ & 1.99 & 0.01 \\
\hline & Mkuze & 31 & 42 & $0 \cdot 74$ & $1 \cdot 66$ & 0.00 \\
\hline & & 67 & 91 & 0.74 & $3 \cdot 65$ & $\overline{0.01}$ \\
\hline V. verrucosum & Duivelskloof & 63 & 58 & $1 \cdot 09$ & 0.21 & - \\
\hline & Zoutpạn & 16 & 24 & $0 \cdot 67$ & $1 \cdot 60$ & 一 \\
\hline & Mkuze & 39 & 52 & $0 \cdot 75$ & $1 \cdot 86$ & 一 \\
\hline & Kranzkop & 52 & 44 & $1 \cdot 18$ & 0.67 & - \\
\hline & & 170 & 178 & 0.96 & $0 \cdot 18$ & 一 \\
\hline
\end{tabular}




\section{(vi) Sex ratio}

The data on sex ratio are summarised for several species in table 5 . Sample sizes are occasionally relatively small due to the difficulty of collecting some species. A few African species have female predominant ratios, e.g. $V$. fischeri (Barlow and Wiens, 1976), V. obscurum, and $V$. subserratum. The European and Asian species, $V$. album and $V$. cruciatum, also have female predominant sex ratios (Barlow et al., 1978).

In most cases, however, the data agree with a sex ratio of $1 \cdot 0$, and where more than one population of a species was sampled, the data appear to be homogeneous. If the translocations have a role in the maintenance of biased sex ratios, it is probably a secondary function occurring only in those species in which distortion of the sex ratio has special selective value, and is not necessarily associated with a meiotic drive system as we originally speculated for $V$. fischeri (Barlow and Wiens, 1976).

\section{General discussion}

This survey shows that translocation heterozygosity occurs extensively among the dioecious species of African Viscum, but is apparently rare among the monoecious species. Since the dioecious species $V$. album and $V$. cruciatum in Europe and Asia, and $V$. alniformosanae Hayata in Taiwan show patterns of translocation heterozygosity similar to the African species (Barlow et al., 1978; unpublished data), this relationship probably extends to all dioecious members of the genus. The only remaining area rich in dioecious species of Viscum, which is not well surveyed, is Madagascar. The Madagascan species, as opposed to the African ones, are apparently based predominantly on $x=13$ instead of $x=14$ (Wiens, 1975), but there is little reason to suspect that their genetic systems are different.

The translocation heterozygosity in Viscum thus emerges as a phenomenon which is characteristic of the dioecious state. As suggested above, some of the translocations may be common to several species, and the translocation systems were possibly established prior to, or during the differentiation of the different species. The translocations, in fact, may have played a fundamental role in the establishment of dioecy in the genus.

There is little doubt that dioecy in Viscum is derived from monoecy. Unisexual flowers are characteristic of all Viscaceae, and monoecy is fixed or predominant in all genera. In most other respects, however, Viscum conforms with the observations or predictions of dioecy in tropical forests made by Bawa and Opler (1975). They concluded that dioecy evolved in response to selection for the enforcement of outcrossing, and suggested a number of factors which may have favoured dioecy as the outcrossing mechanism. These include (i) the likely genetic simplicity of dioecy compared with self-incompatibility (Baker, 1967), (ii) high levels of reproductive failure in self-incompatible hermaphrodite or monoecious species because of the small foraging ranges of the pollen vectors, and (iii) escape from seed predation caused by altered size and distribution of seed set. Possibly all of these factors have contributed to the evolution of dioecy in Viscum.

If dioecy is established by mutations affecting different hormone systems which favour maleness and femaleness (Audus, 1972; Bose and Nitsch, 1970 ), then such genes would likely be non-allelic. This possibility was 
argued on a priori grounds for angiosperms generally by Ross and Weir (1976) and Charlesworth and Charlesworth (1979). These authors also point out that mutations for dioecy are not likely to accumulate simultaneously, and that in many cases gynodioecy, through male sterility, is an intermediate step. If the genes for full dioecy were not linked, recombination could produce males, females, hermaphrodites and neuters, and Charlesworth and Charlesworth (1979) suggest there might often be a "linkage constraint", such that unlinked genes for dioecy may be selected against. Thus genes for dioecy should occur on the same chromosome, with no crossing-over between loci, so that particular chromosomes become identified with sex determination.

If these constraints apply in Viscum, then translocations should have a role in the evolution of dioecy, namely in bringing the non-allelic sex factors into close linkage. In the simplest case of sex determination involving two loci on different chromosomes, a reciprocal translocation involving these two pairs of chromosomes would bring the genes into linkage, and generate a sex-associated $\odot 4$ (fig. 3, a). If this linkage was achieved indirectly, through an intermediate translocation, a sex-associated $\odot 6$ would result (fig. 3, b). These translocations would allow a rapid shift to full dioecy through the elimination of recombination producing hermaphrodites.

Our data suggest that in many species of Viscum dioecy is stabilised in this way, and that this system for maintaining dioecy is conserved during the differentiation of new species. However, subsequent modifying translocations may be occasionally incorporated into the system, especially where they would tighten the linkage between the sex-determining loci. Strong selection pressure would exist for such restriction of recombination (Charlesworth and Charlesworth, 1979). This possibly is the case in the sex chromosomes of Silene dioica, where crossing-over occurs only in the regions outside the sex loci (Westergaard, 1958).

In the models shown in fig. 3, rearrangements in the sex-associated multivalent bring the sex determination loci together in a single chromosome, thus eliminating the sex-associated multivalent. Where the sex-associated multivalent is $\odot 6$ or larger, as in the second model (fig. $3, \mathrm{~b}$ ), the rearrangement has the effect of releasing the remaining components of the translocation complex from sex-association. As suggested above, a new floating translocation would result. This model therefore explains the existence of a few diverse dioecious species of Viscum, at the extremity of its geographical range, which do not have a fixed sex-associated translocation complex. It is also consistent with the apparently increased level of floating translocation heterozygosity found in some of these species.

Thus, translocations in Viscum may play a fundamental role in the establishment of dioecy, with sex-associated translocation heterozygosity being an intermediate stage in the attainment of close linkage between the sex determining loci. Perhaps this sequence is a simple consequence of randomness of the translocation events, because an initial exchange directly involving the chromosome arms bearing the sex determining loci could establish close linkage without enforcing translocation heterozygosity. Apparently this has not happened in Viscum.

Even if this model for the evolution of dioecy in Viscum is correct, translocations are perhaps of further adaptive importance in the genus. Floating translocations are common even in species like $V$. hildebrandtii which retain 


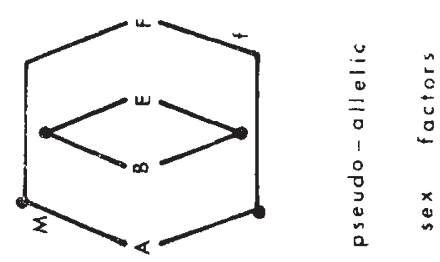

$\uparrow$
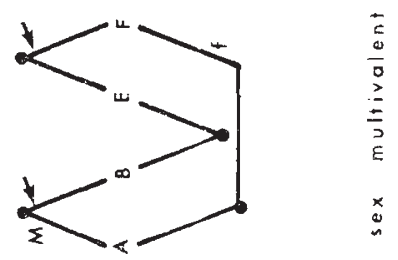

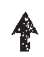

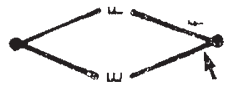

$\pi$

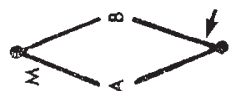

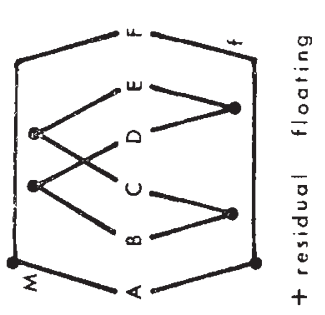

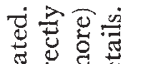

要

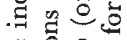

ส.

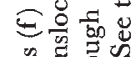

论

s

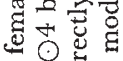

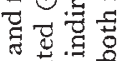

$\uparrow$

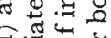
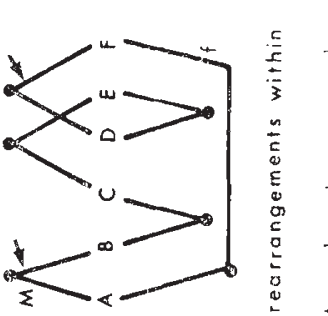

1

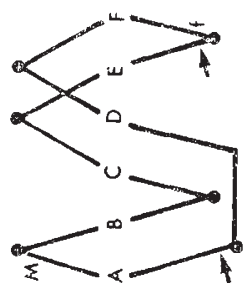

运

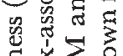

(5)

范范.

เ

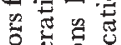

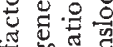

तो

的芯

웡웡

ㄷำ

㻤空完

ज药 总

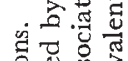

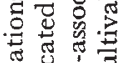

导预芯

预芯芯志

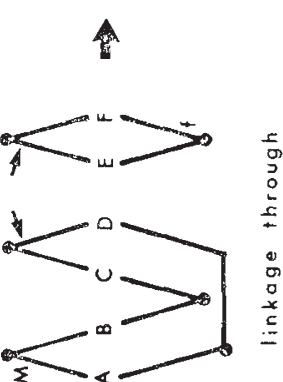

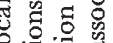

至苞

过造造品

क्षित्त

궁

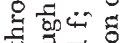

ई윯

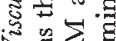

题

घ तี

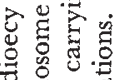

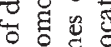

. 㝴 है

पै ह

必然

亏ิ

舫

웡

类焉

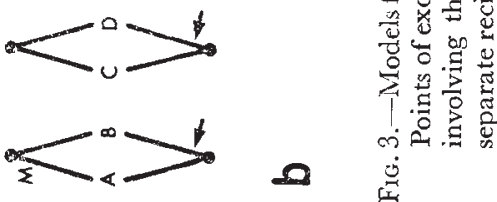


the sex-associated multivalent, and they are also retained in species like $V$. obscurum which may have lost the sex-associated multivalent. Their persistence in high frequency indicates a more basic role in the genetic system of Viscum, presumably as a means of maintaining high levels of heterozygosity. But why have translocations accumulated only in dioecious species and not in monoecious species? Perhaps the fixation of translocation heterozygosity by sex-association allows time for the accumulation of adaptive gene combinations in the translocation complexes, thus giving them immediate selective value when released as floating translocations. Such complexes would have more likelihood of being conserved than raw exchanges directly exposed to selection, as would be the case in monoecious species.

Acknowledgements.-This study was supported by grants from the U.S. National Science Foundation and the Flinders University Research Committee. We gratefully acknowledge the assistance of many individuals and institutions who contributed to the study including Drs J. O. Kokwaro and R. Robbins of the University of Nairobi, Kenya, Mr M. Gilbert of the East African Herbarium, Nairobi, and Mr P. van Wyk, Kruger National Park. A major portion of this study was completed while the first author was an invited Research Fellow at the Botanical Research Institute, Pretoria, South Africa. We are especially indebted to the Institute for financial support, the use of laboratory and field facilities, and the generous co-operation of the staff, especially the Director, Dr B. DeWinter. C. Wiens and W. H. Busby provided indispensable laboratory and field assistance.

\section{REFERENCES}

AUdUs, L. J. 1972. Plant Growth Substances. Leonard Hill, London.

BAKER, H. G. 1967. Support for Baker's Law-as a rule. Evolution, 21, 853-856.

BARlow, B. A., AND WIENS, D. 1975. Permanent translocation heterozygosity in Viscum hildebrandtii Engl. and V.engleri Tiegh. (Viscaceae). Chromosoma (Berl.), 53, 265-272.

BARLOW, B. A., AND WIENS, D. 1976. Translocation heterozygosity and sex ratio in Viscum fischeri. Heredity, 37, 27-40.

BARLOW, B. A., WIENS, D., WIENS, C., BUSBY, W. H., AND BRIGHTON, c. 1978. Permanent translocation hcterozygosity in Viscum album and $V$. cruciatum: sex association, balanced lethals, sex ratios. Heredity, 40, 33-38.

BAWA, K. S., AND OPLER, P. A. 1975. Dioecism in tropical forest trees. Evolution, 29, 167-179.

BLoом, w. L. 1977. Translocation heterozygosity, genetic heterozygosity, and inbreeding in Clarkia speciosa. Evolution, 31, 256-264.

воSE, T. K., AND NITSCH, J. P. 1970. Chemical alteration of sex expression in Luffa acutangula. Physiologia Pl., 1206-1211.

ChARLESWORTH, B., AND CHARLESWORTH, D. 1979. A model for the evolution of dioecy and gynodioecy. Amer. Nat. (in press).

DANSER, B. 1941. The British-Indian species of Viscum revised and compared with those of South-Eastern Asia, Malaysia, and Australia. Blumea, 4, 261-319.

JонN, в. 1976. Population Cytogenetics. Edward Arnold, London.

MECHELKE, F. 1976. Sex-correlated complex heterozygosity in Viscum album L. Naturw., $8,390$.

MULleR, H. J. 1925. Why polyploidy is rarer in animals than plants. Amer. Nat., 59, 346-353.

Ross, M. D., AND WEIR, B. s. 1976. Maintenance of males and females in hermaphrodite populations and the evolution of dioecy. Evolution, 30, 425-441.

WESTERGAARD, M. 1958. The mechanism of sex determination in dioecious flowering plants. Adv. Genet., 9, 217-282.

WIENS, D. 1975. Chromosome numbers in African and Madagascan Loranthaceae and Viscaceae. Bot. F. Linnean Soc., 71, 295-310.

WIENS, D., AND BARLoW, B. A. 1973. Unusual translocation heterozygosity in an East African mistletoe (Viscum fischeri). Nature New Biol., 243, 93-94.

WIENS, D., AND BARlow, B. A. 1975. Permanent translocation heterozygosity and sex determination in East African mistletoes. Science, 187, 1208-1209. 

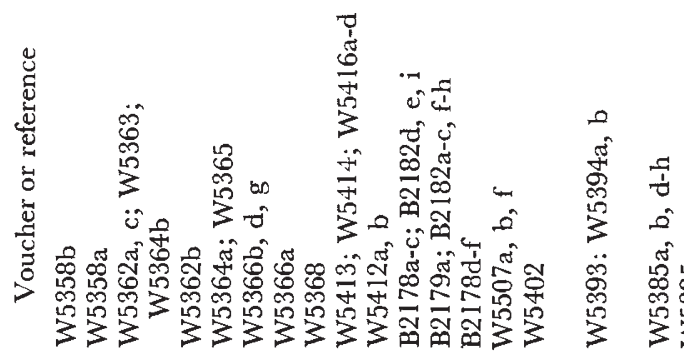

似

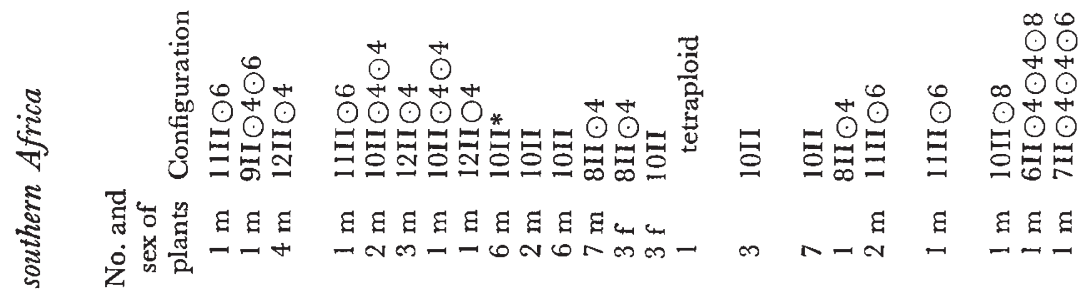
¿

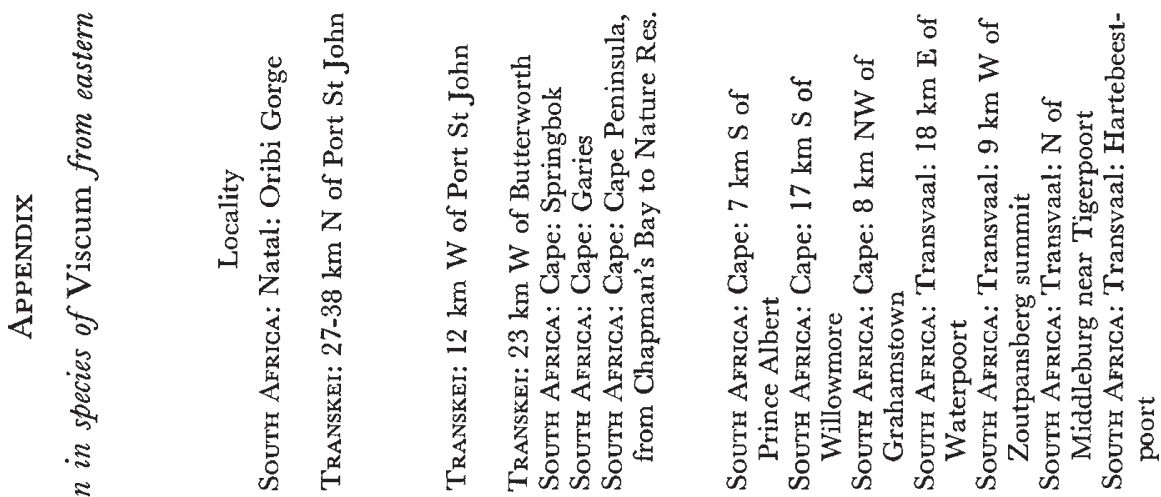

恚

인

$\underline{\underline{1}}$

$\uplus$

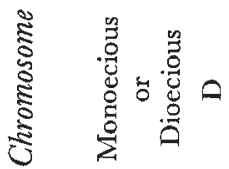

$+$

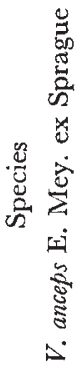

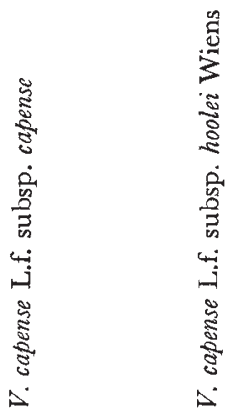

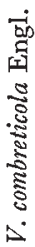




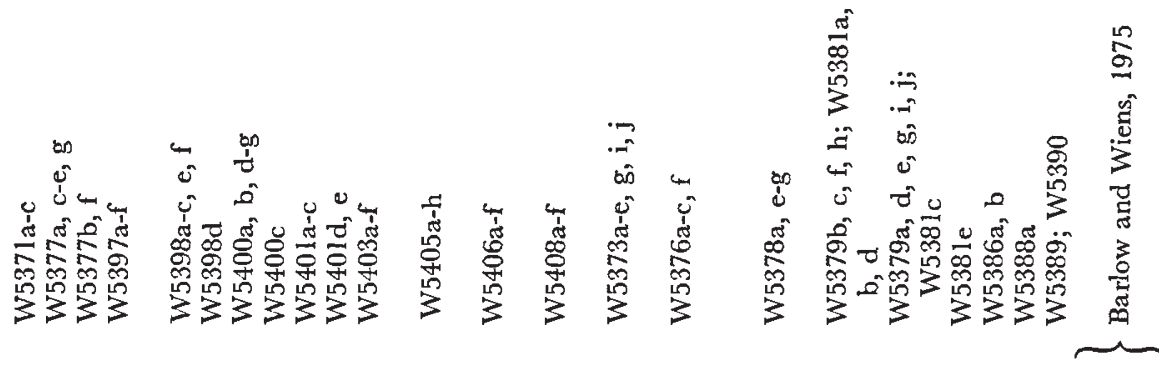

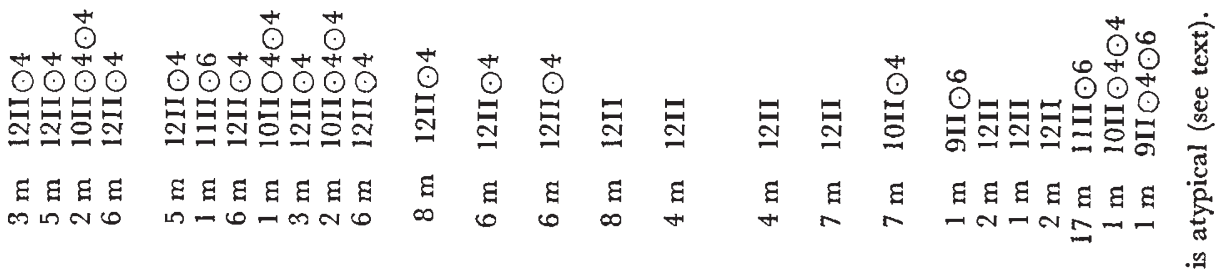

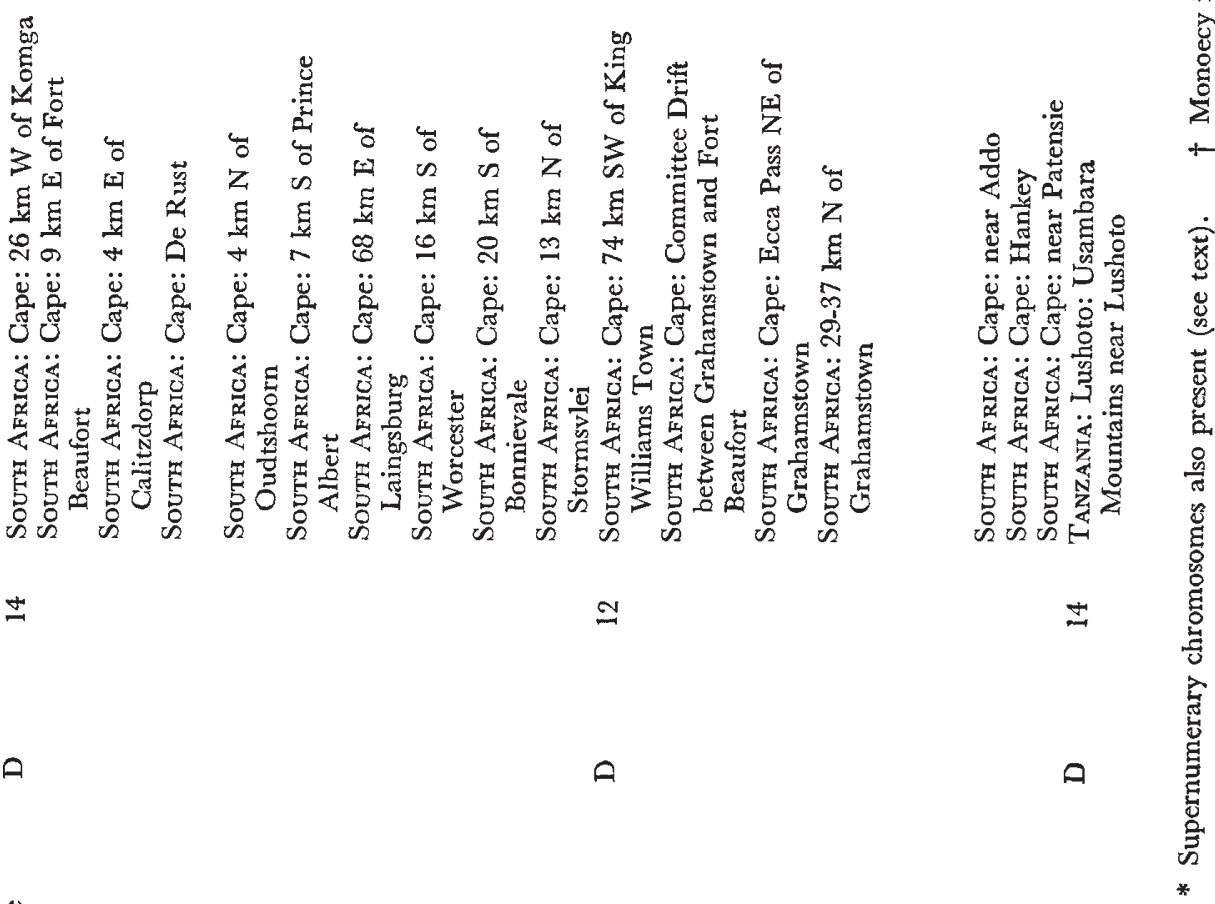




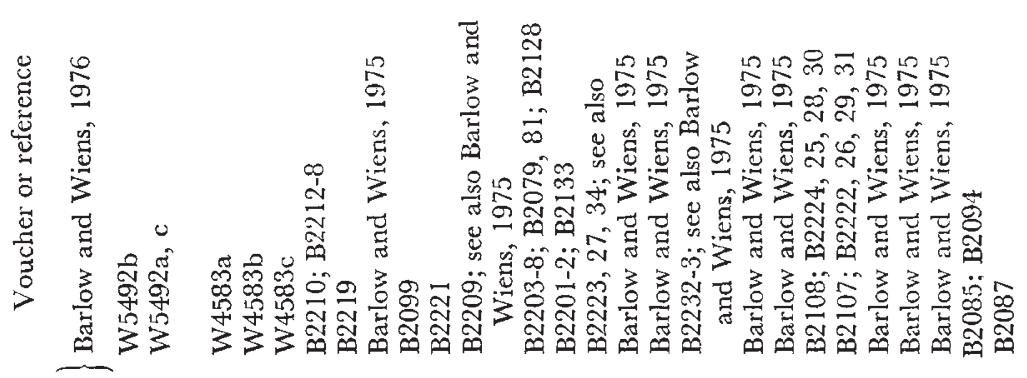

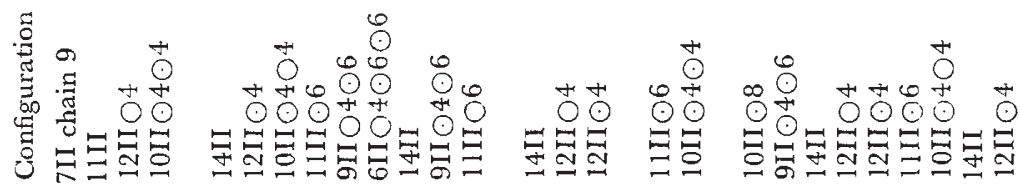

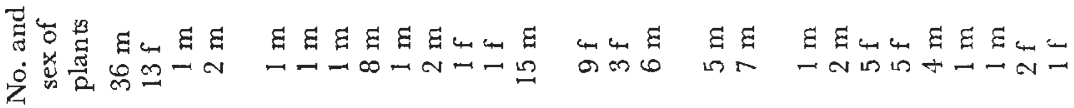

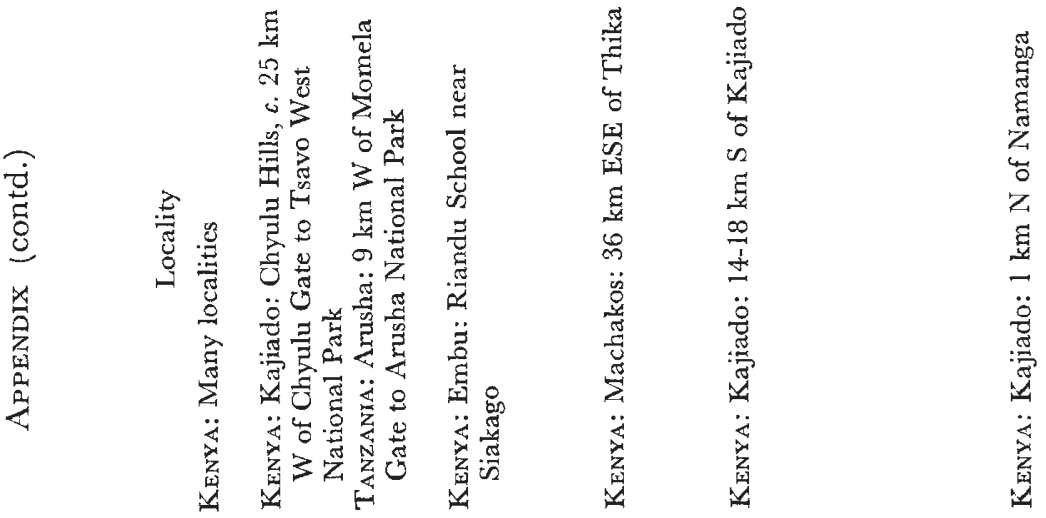

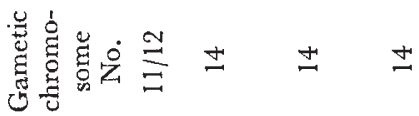

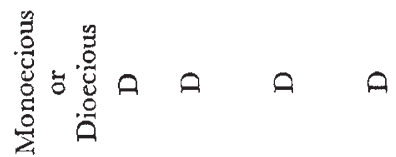

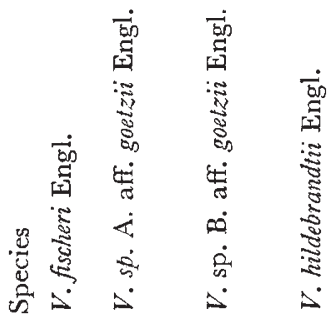




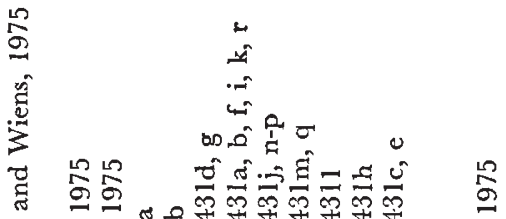

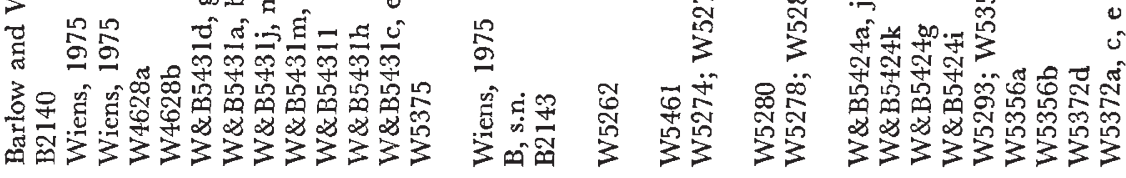

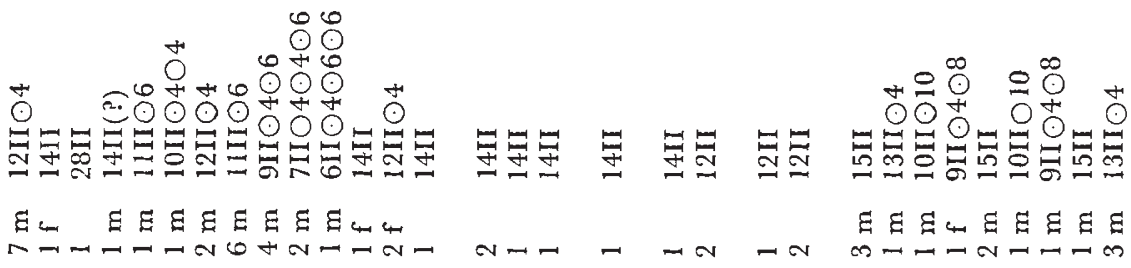

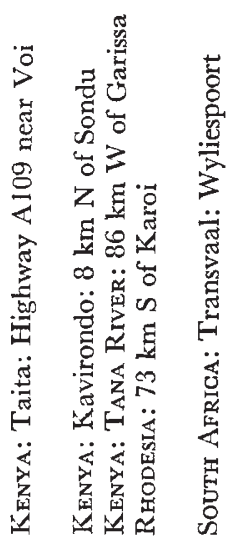

$\stackrel{\infty}{\sim} \pm$

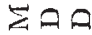

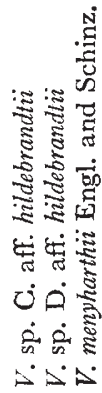

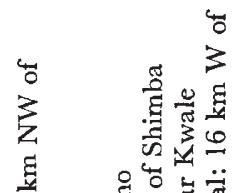

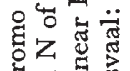

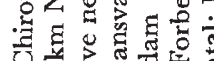

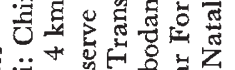

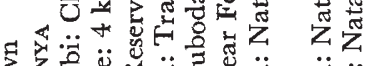

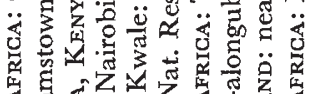

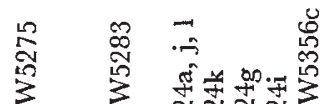




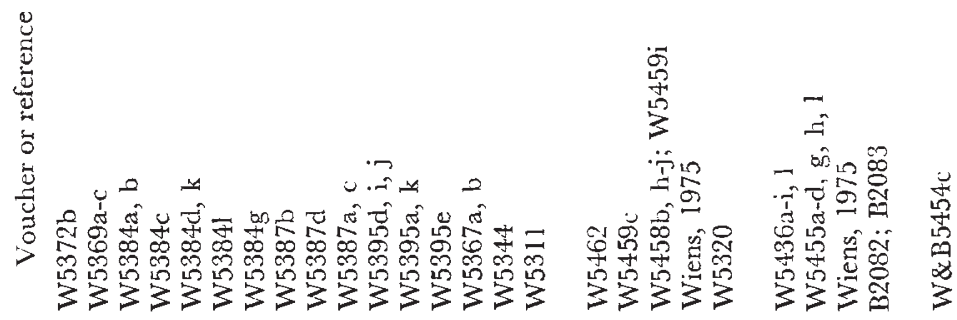

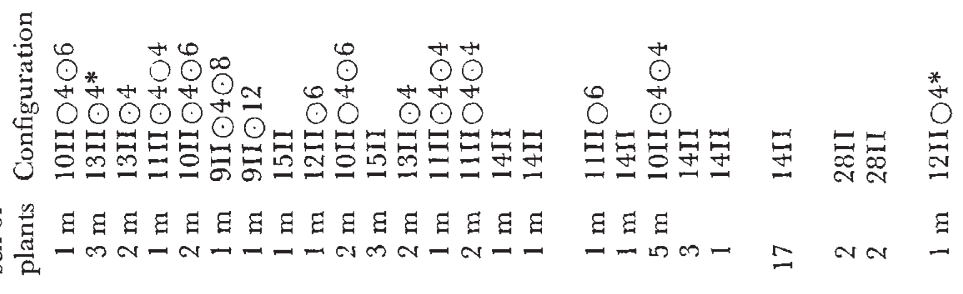

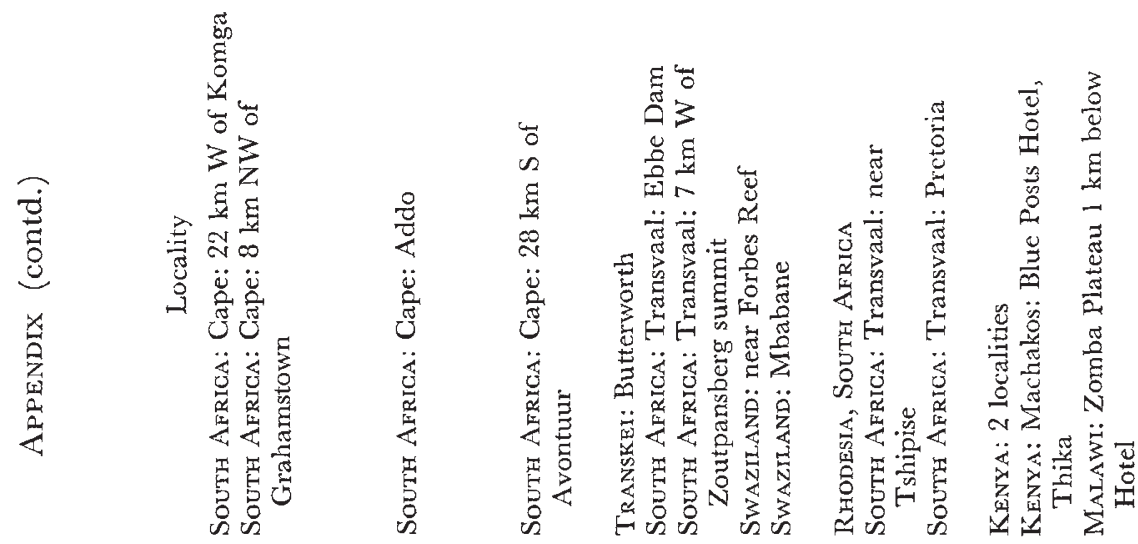

总㤩

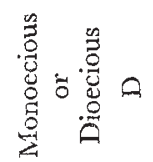

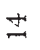

2 $\pm$

$\stackrel{\sim}{\sim}$

$\Sigma$

$\bar{z} \quad 0$
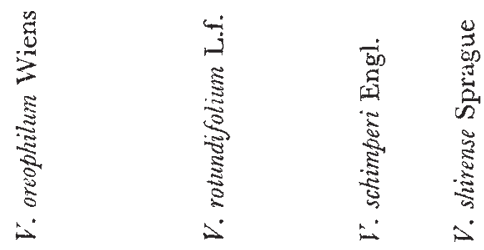


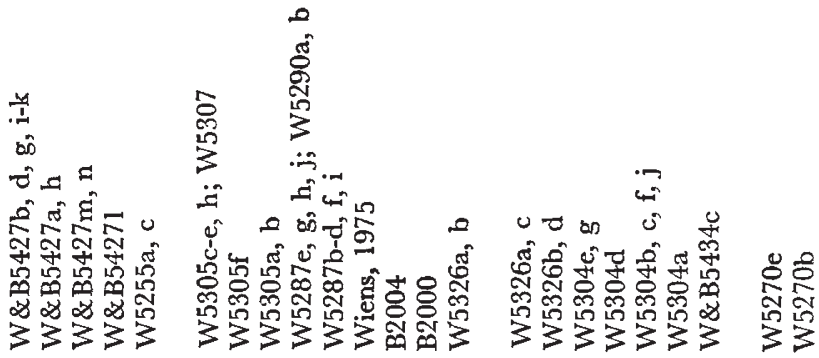

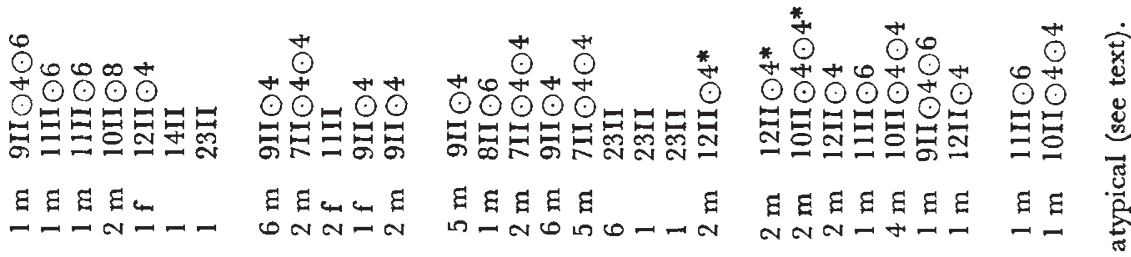

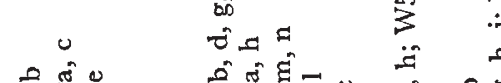

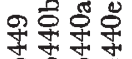

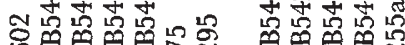

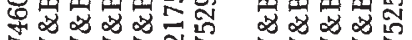
33333 33333

究

跣

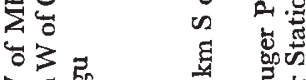

3 를

g은

을 苍

究

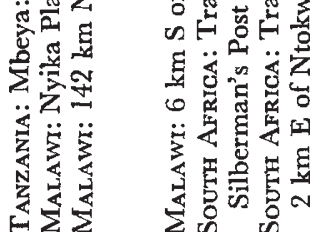

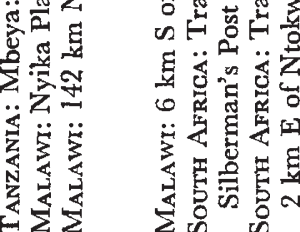

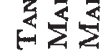

$\pm$

むึ

D 芝玄

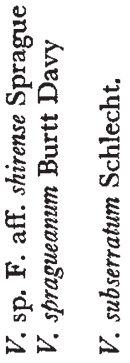

$42 / 2-G$

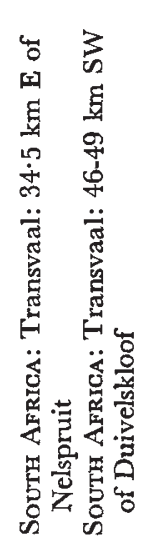


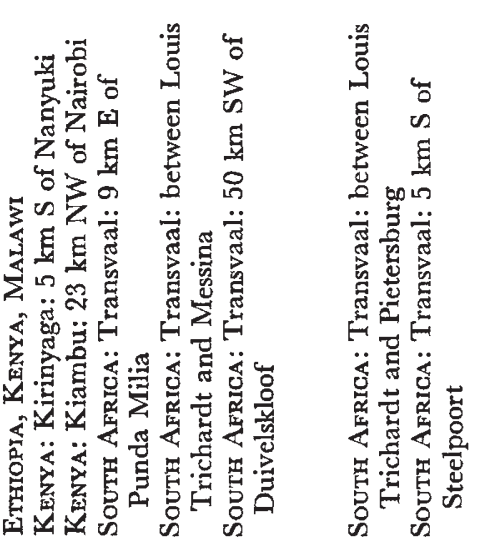

กิ
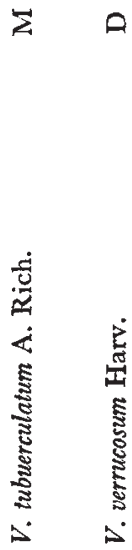


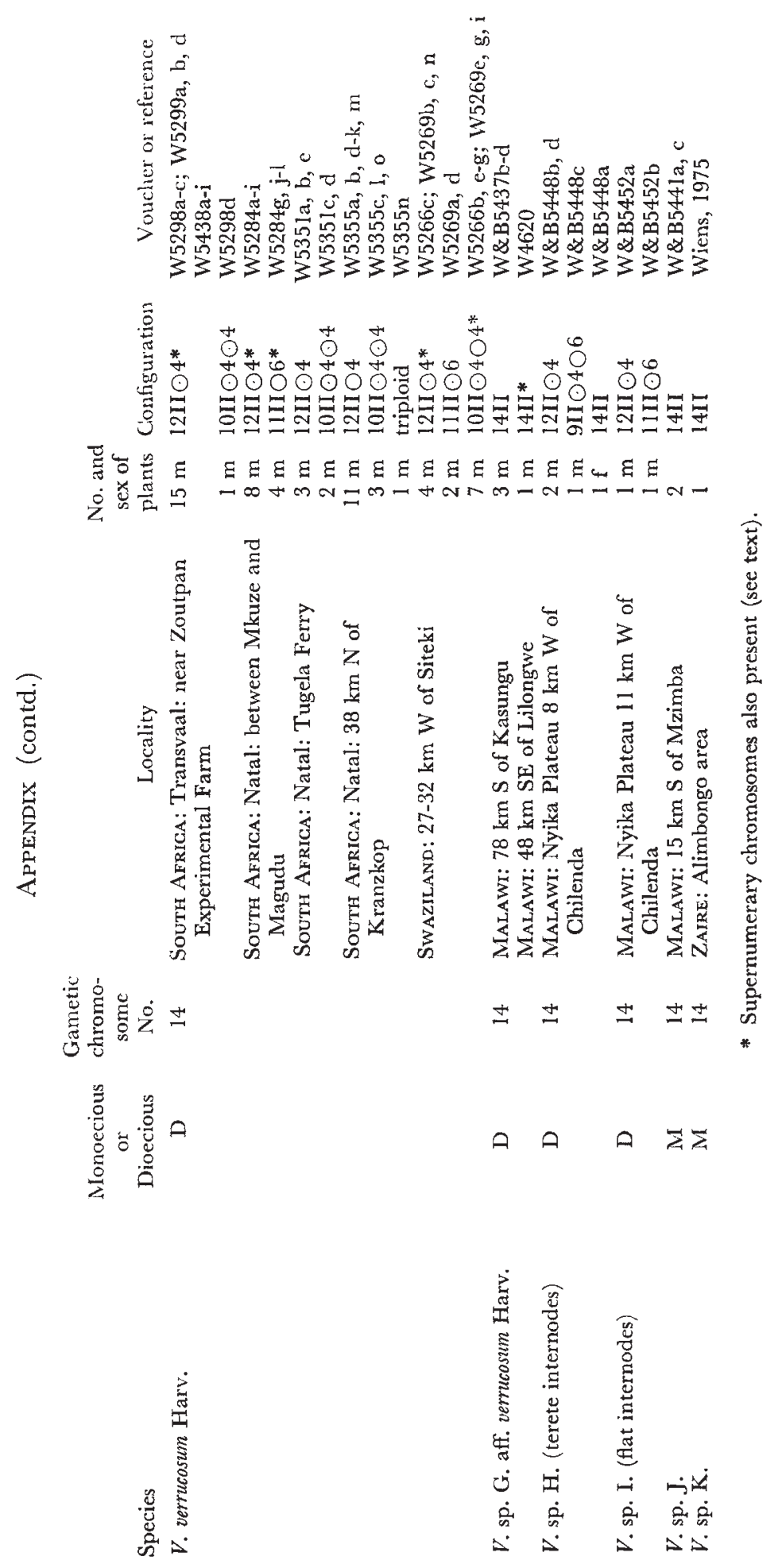

